\title{
Risk Management of Construction Projects
}

\author{
Amer Abdullatef Mahmoud al-Mukahal ${ }^{1}$ \\ ${ }^{1}$ Faculty of Engineering, Jordan University, Jordan \\ Correspondence: Amer Abdullatef Mahmoud al-Mukahal, Faculty of Engineering, Jordan University, Jordan. \\ E-mail: Amerabosaea@gmail.com
}

Received: April 13, 2020

doi:10.5539/emr.v9n1p15
Accepted: May 12, 2020 Online Published: May 15, 2020

URL: https://doi.org/10.5539/emr.v9n1p15

\begin{abstract}
This study aims to Analyzing the nature of Construction Projects, Analyzing the Nature of Construction Projects Risk, and Analyzing The mechanism of Risk Management. This Study adopted The Quantitative Method. The Summary Concluded From The Study Lies in the Theoretical Study of construction Project's Risk. The Construction Project Contains Many Risk Which Related to Different Factors:

Legal, Organizational, Technical, Zoning, Financial, Social and Political Factors. The Process of Management of Construction Projects includes:

Planning of Risk Management, Risk Identification By (Checklist Analysis, Questionnaire, Personal Interview, Brainstorming Technique, Delphi Technique), Risk Analysis By Qualitative Analysis By (Probability and Impact Assessment, Cause and Effect Diagram, Probability and Impact Matrix) and Quantitative Analysis By (Probability Distributions, interviews, Sensitivity Analysis, Fault tree, Events tree, Munte Carlo Simulation), Planning the Response to Risk By (Strategies for Response to Negative Risk , and Strategies to Positive Risks), and Risk Control and Cheek. Depending on The Conclusions, The Study Recommends the Following:
\end{abstract}

- Process of Assessing The Efficiency of Construction Companies.

- Use Qualitative Analysis and Quantitative Analysis in The Process of diagnosis, and Categorization of Risk in the Process of Risk Management.

- Studying Types of Contracts of Construction Projects.

Keywords: construction projects, qualitative analysis, quantitative analysis, management of construction projects

\section{Introduction}

Construction sector consists of a group of activities, which are related to engineering construction works of various kinds. This sector is characterized by a close relationship with all other economic sectors. This is why it is an important and reliable indication to movement of the national economy and its trends. However, there are many risks that are faced by the construction projects. These risks may negatively affect the on time, cost and quality of the project. These risks might be inherent or apparent, or interact with each other. In addition to that, it is hard to avoid these risks or predict them with a high degree of accuracy, or their effect on the project. These risks relate to the work environment, economic policies, political events, social aspects, climate environment, government laws and regulations (Migdadi, 2016; Newton, 2015). Based on the aforementioned the study problem is represented by the following questions:

1) What is the nature of construction projects management?

2) What is the nature of risks in construction projects sector?

3) What is the nature of the process of risk management of construction projects?

This study aims at achieving the following objectives:

1) Analyzing the nature of construction project in terms of concept, topics, processes, and life cycle of construction project management,

2) Analyzing the nature of construction projects risks in terms, concept, and types, 
3) Analyzing the mechanism of risk management of construction projects in terms of its concept, risk management process, risk identification tools, techniques for qualitative analysis of risk, techniques for quantitative analysis of risk, and risk response strategies.

The study has three main hypotheses which are represented as follows:

$\mathrm{H}_{\mathrm{A} 1}$ : There is a special nature of the construction projects.

$\mathrm{H}_{\mathrm{A} 2}$ : There is a special nature of the construction projects risks.

$\mathrm{H}_{\mathrm{A} 3}$ : There is a mechanism for analyzing risks in construction projects. Through this mechanism, the negative effect of these risks on the construction project's objectives is reduced.

The study adopted the quantitative method by which library survey is conducted, and study of theoretical studies and research in order to crystallize the principles and theoretical bases that the theoretical framework of this study is based on.

The significance of this study lies in two main levels:

The first level: The theoretical level

The theoretical significance of this study lies in the academic field as it provides a reference in the construction research field, where this study provides theoretical frameworks for the nature of construction projects, the nature of construction sector risks, and the nature of risk management of construction sector, which will help researchers, academics, and experts in this sector to generate ideas, and concepts to conduct different studies and research in this sector in terms of methodology, targeted group, and countries in addition to the possibility of linking these research with different fields and different cognitive sciences, which will lead to reduce the gap in the construction search field.

The second level: The practical level

As far as the practical base is concerned, this study provides a clear conception of the risks that this sector is exposed to, how these risks are qualitatively and quantitatively analyzed as well as risk identification tools, and risks response strategies, which will help decision-makers in this sector learn about the nature of these risks in all their aspects in a way that helps generate ideas through which plans and strategies are formulated, which are based on principles, standards, and correct, clear, and scientific methodology, that is compatible with the variables and international standards, which will help reduce the negative effect of risks in a way that contributes to the success of projects of this sector.

\section{Literature Review}

\subsection{Nature of the Construction Projects}

\subsubsection{Concept of Construction Projects Management}

According to modern management concepts, construction projects management is defined as an effective management which plans and controls the project's activities. It also schedules its activities properly, and takes the necessary measures to speed up performing activities to fulfill the obligation of accomplishing the project in time. The role of management in construction projects is not only limited to a specific phase of project performance phases but also begins as the project starts, and does not end until the project ends. Thus, the management has to identify all requirements for each one of the activities as well as the simultaneous activities, which are performed together at the same time. The chokepoints and the potential components should also be identified to deal with them or avoid them. The time line for achieving each activity and its beginning and end date should also be identified with a coordinated distribution of material and human resources. One of the duties of construction projects management is to analyze deviations which occur during the preparation of control reports, and then to take the necessary corrective measures to correct the situation (Gabel, 2013). The concept of construction projects management is based on several topics as indicated by Loader (2006), (Musa et al., 2012) and is represented as follows:

The first topic: Scope

The construction project has known objectives, and the scope in the project is identified during the life cycle of the project.

The second topic: change

There are many predictions that a change would occur in the construction project, which requires performing the processes that tend to control this change and reduce the negative effects resultant from it. 
The third topic: planning

Construction project management aims to set a high level of information for detailed plans through the project's life cycle, which requires gradation capacityin injecting this information.

The fourth topic: management

Manger of construction project takes the responsibility for project management, and also manages work teams to achieve the project's objectives.

The fifth topic: success

The success of construction project is measured by the project's quality, timeline, and commitment to budget.

The sixth topic: control

Manger of construction project controls and monitors the results of project's works which have been agreed upon.

\subsubsection{Processes of Construction Project Management}

Processes of construction project management can be divided as indicated by (Migdadi,2016),(Meredit et al., 2012) into the following:

\section{1) Management of construction project completion}

The scope of knowing project completion management includes processes and required activities to identify, collect, unify, and coordinate different processes, and activities of project management, and manage the predictions of interested parties successfully to meet the project's requirements.

2) Management of construction project scope

The Process of management of construction project scope includes all the necessary processes to accomplish the project successfully.

3) Management of construction project time

management of construction project time includes all processes, tools, and technical methods necessary for accomplishing the project on time.

4) Management of construction project cost

Cost management includes processes of cost assessment, and setting budgets to accomplish the project within the adopted budget. The calculation of project cost is not only related to direct cost calculations, which result from performing the project but also include the former phases of process of carrying out the contract with the employer, which includes as well the indirect cost, such as administrative expenses, loan interests, the cost related with the project accomplishment time.

\section{5) Management of construction project quality}

Project quality management includes all processes and activities which determine the quality policy, its objectives, responsibilities, application through policy, measures and constant improvement processes which are applied for the duration of the project.

6) Human resources management of construction project

Human resources management of construction project includes all the processes of organizing and managing project team in a manner that encourages commitment to the project.

7) Communications management of construction project

It includes all processes which ensure generation, collection, circulation, storage, and retrieval of information to make use of it in time.

8) Risk management of construction project

In includes the processes related to planning, identifying, analyzing, facing, monitoring, and controlling risks.

9) Purchases management of construction project

It includes all processes to purchase and obtain all products and services necessary for performing the work.

10) Management of interested parties of construction project

It includes all the processes necessary to determine the identity of people or organizations, which could affect or be affected by the project in order to analyze their predictions and its effects on the project, and formulation of 
appropriate strategies to engage them in decision-making, and perform the projects effectively.

\subsubsection{The Construction Project's Life Cycle}

The project's life cycle is divided into basic phases, which are represented by beginning, planning, execution, following up, controlling, and closing. It comprises the course of the construction project from beginning to end, and life cycle of projects management as referred to by (Nepal, 2014; Pieplow, 2012; Macro, 2014) and is represented as follows:

The first phase: beginning of project construction

It includes the process of identifying the nature of construction project and its range through understanding the environment work, and ensuring the control of all project requirements, and preparation process (beginning phase) includes the following steps:

1) Analyzing the construction project requirements in a standard way -in other words dealing digitally with the project parts including the time, labor, raw materials, and financing.

2) Reviewing the current operation capacities as an initial phase of assessing the available potentials of the company to perform the construction project.

3) Financial analysis of input and output, which includes the average spending in the construction project.

4) Analytical assessment to distribute tasks in a more efficient way between elements of work team in the construction project.

5) Creation of a detailed map of the work phases in terms of tasks, cost, delivery schedules, and expiration of the project.

The second phase: construction project planning

This phase includes project planning to guarantee compatibility between the elements of time, cost, and resources and the average work to be done, while assessing accepted risk factors. This phase comprises the following steps:

1) Identifying a strategy and proper planning model to carry out the project as a serial plan.

2) Development of dealing with available resources in the most efficient way.

3) Selecting the appropriate planning and designing team.

4) Sorting out priorities and delivery phases, and identifying the track of operational activities in the course of construction project.

5) Assessing the required resources and the estimated budget for all the operational activities in the course of project.

6) Developing work schedule in a way that matches with requirements of carrying out the project.

7) Planning to deal with potential risk factors in the course of the project.

8) Obtaining the official approvals to start work.

9) Ensuring the smoothness of communication between project coordinators. It is preferred that there is a conceptual model of the construction project and its processes so that it helps in identifying what is required to achieve and delivering it in the required precision.

The third phase: carrying out the construction project

After obtaining an approval for an action plan, the action plan is translated into execution. The project manager's task in this phase is to keep the action plan on the right track, and to communicate with all members of the project to provide necessary guidance, and to control work quality and spending, and to be on the right track in terms of assets, resources and budget tools.

The fourth phase: Following up the construction project

It includes the control process of execution phases, its levels, and initial output. This phase includes the following activities:

1) Phasic measurement: assessment of cost, effort, potentials, and how compatible they are with the drawn-up plan to reach the objectives of the construction project.

2) Applying practices which correct the work track in case they were needed. 
3) Controlling factors that lead to departing from the complete application of work parts, particularly in multi-phases projects, where controlling and checking the source of feedback is in the advanced phases to correct any tracks incompatible with what is required to do.

The fifth phase: termination/closing

This phase represents the delivery phase and includes the following activities:

1) Termination of the construction project by terminating all activities included by the project with documentation of executive phases as a future work and information reference.

2) Termination of contracts which include reviewing and accrediting contracts at the expiration of project by all parties participating in the construction project.

\subsection{Nature of Construction Projects Risks}

\subsubsection{Concept of Construction Projects Risks}

Risk in construction projects can be defined as an uncertain event or case from which a positive or negative effect on the construction project result (Qasem, 2012). (Raftery, 2003) defines it as deviation from the wanted, expected or hoped result of the construction project. From the viewpoint of (Simu, 2006), it is uncertainty that is related to the occurrence of some loss. Furthermore, (Tetteh, 2014) defines it as the possibility of the occurrence of loss, damage, negative consequences in the ongoing construction project. Risk in construction projects include a cause and a resultant effect, for example, the cause is the qualified, limited, and available workforce of the project, or this work force is unsuited to the tasks that are assigned to it. There fore, the result or consequence will be visible in the additional cost, or fault in scheduling work, and the length of execution time. There are known risks, which have been diagnosed and became possible to plan in order for them to be controlled. On the contrary, unknown risks cannot be managed. However, the project managers can deal with them through implementing general contingency plans, which are based on the past acquired experience through carrying out former projects. There are risks which are considered as opportunities, and these are risks that threaten the project's success, but they are accepted when a budget is set for them in return of what will result from them (Wallo, 2015; Varsh et al., 2015).

\section{Types of risks in construction projects}

In consequence of environmental factors, and what follows them from technological developments, which added the capacity of change in construction projects ,this made construction projects exposed to various types of risks, some of them are related to the work environment, some are related to economic policies, and some are related to social aspects. These risks might be changeable or fixed. Here is an explanation of the risks of construction project as indicated by (Akab, 2009).

First: legal risks

It means a lack of or non-existence of legal vision for requirements and potential modifications in the following aspects:

- Safety terms.

- Regulations related to environment and urban planning.

- Noise.

- Purchase of properties.

- $\quad$ Submitting tenders.

- Exemptions and forgiveness.

- $\quad$ Procedures which are related to public places and regional planning.

The possibility of bringing lawsuits, which is represented by the following:

- Lawsuits by the beneficiaries as a consequence of mistakes in performance or a fault in the terms agreed upon in the contract documents.

- Lawsuits by the municipality due to the failure to fulfill agreements, or damages to the surrounding areas of the project.

- Lawsuits by neighboring residents due to damages to their homes or businesses.

- Mistakes committed by contractors or projects executors in connection with legal procedures. 
- $\quad$ Mistakes committed by projects executors in relation with sticking with regulations during carrying out the project.

Second: organizational risks

It means modifications in the program of project requirements as a result of the following:

- A change in defining or identifying the project.

- Non-existence of clear procedures for the project.

- Special procedures of the potential modifications, planning, costs assessment, and others.

- Procedures of accomplishing the project, and accepting it by the beneficiary.

- Administrative procedures.

- Procedures of submitting and granting tenders.

- Rewards procedures.

- A lack clarity related to special procedures of requirements, which are laid down by customer, manager, municipality, and city.

- Failure to agree with different parties, which are related to the project.

- A lack or non-existence of good communications (whether internal or external) or non-completion of communications plan.

- Nonexistence of a clear plan for quality.

- No clarity of the project's limits.

- No internal coordination between the secondary projects in the total project.

- Not taking other projects into consideration whether partially or totally.

- A lack of specialized human resources of a specific part of the project due to issues in project's organization, taking in some individuals who have rare specialization, or making modifications to the project's cadres.

- A delay in requiring materials that the project needs.

- No precision or non-completion of different time assessments of project's parts.

- Non-completion or not taking interest in special contractual documents of the project.

Third: technical risks

- Incorrect assessment of the required technology, building ways, or project's phases.

- Modifications to design, ways, building, and execution.

- Extra work to link current achievement with a former one.

- Adopting creative methods or new work ways of execution.

- Design modifications that made during execution.

- Unwise assessment of the quantities of necessary materials to carry out the project.

- Disappointing performance by contractors whether executors or designers.

- No availability of required materials.

- Mistakes in execution.

Fourth: Zoning risks

- The presence of obstacles for work in the execution place.

- There are artifacts or what indicates that the area is archeological.

- There are pipes, and cables related to sewerage services, and others.

- Not providing an appropriate climate for execution, such as snowfall periods, or storms that last long.

- There is pollution in the area, which leads to the complication of the execution process.

- The quality of the land is not appropriate in terms of its ability to withstand constructions.

- Insufficient considerations with regard to vegetation resources in the place of project execution. 
- Additional costs to protect the areas of groundwater.

- There is no infrastructure in the execution place.

- The need for building utilities as well as passage facilities and safety means.

Fifth: Financial risks

- An increase in the prices of the materials used in carrying out the project.

- Changes in interest rates.

- Bankruptcy which one of the contractors, suppliers, or beneficiaries of the project could be exposed to.

- No precision in fulfilling obligations towards the executors.

- A lack of obtaining financial information.

- Change in exchange rates.

- Devaluation of currency.

- Deviation resultant from tax assessments.

Sixth: social risks

- A lack or no communications with the affected by carrying out the project in the area, and no procedures to encourage their participation, and taking advantage of the project.

- Exaggeration in assessing the social performance during carrying out the project.

- No measures to limit the negative effects and damage to the society in the execution area.

- The occurrence of a direct damage to another party during execution.

- A delay which could result because of demonstrations or project's besieging by the residents of project execution area.

- Incorrect assessments about the necessary measures to know how means of transportation are needed to ensure not to disturb the society in the execution area, transporting equipment and material without creating any problems for the residents.

Seventh: political risks

- The failure to obtain approvals to do some necessary works in time.

- No awareness among the political bodies of the significance and seriousness of some of the quickly required procedures.

- No agreement or difficulty in agreeing with the municipal bodies, and cities councils, or other political bodies.

- Issues relating to adopting regional plans, or plans for areas organization inside the city.

- Issues about the supply matter, and chances for dealing with specific bodies.

- No clarity of the vision of municipal, administrative, political bodies of things related to execution ways, general design of city maintenance ways, coordination of infrastructures between different projects, and the relationship of all that to the infrastructure, and its protection.

\subsection{Nature of Management of Construction Projects Risks}

\subsubsection{Concepts of Risk Management in Construction Projects}

The aim of risk management in construction projects is to execute construction projects in time, within the adopted budget, and the required quality. Risk management in construction projects means planning, organizing, guiding, and controlling potential threats in the construction project, analyzing and assessing these threats, and exercising the necessary policies and procedures to limit and control the negative effects of these threats (AL_Amerah, 2007; AL_Rsheed, 2005).

\subsubsection{Process of Risk Management in Construction Projects}

The process of risk management in construction projects depends on a serious of complete and comprehensive processes, which take into account all the available scenarios that limiting risks, which obstruct the process of achieving the construction project's objectives. These processes are as follows:

The first phase: planning of risk management 
It is a process to identify the way through which activities of project risk management are applied. The significance of planning lies in providing the resources, time, and establishing rules for risk management activities.

The second phase: risk identification

This phase aims at discovering and recognizing all potential risks that the project is facing. These risks might threaten the project's objectives totally or partially (Sonmez, 2002). Risks are identified through the following tools as indicated by (Rejeedh, 2006; Abdullah \&Ahmad, 2018; Williams, 2008):

1) Personal interview: It is a process of investigating facts through information gathering technique either face to face or by telephone. This is done with experts or participants in the project, interested parties, and material experts. Its aim is to identify risks and to recognize them.

2) Checklist analysis: Risks are recognized depending on the information and historical knowledge, which has been acquired from former similar projects, ther sources and information. It is a part of procedures of quality insurance documents of the organization. The minimum level of risks segmentation structure can be used as a risk checklist. The team should make sure of discovering the elements that do not appear in the check-list. These elements should also undergo review during project closing to make use of them in future projects.

3) Questionnaire: It is a group of miscellaneous questions, which are related to each other in a way that achieves the project's objectives. When designing a questionnaire, the following has to be taken into consideration:

- Identifying the required objectives of preparing the questionnaire in the light of the construction project's objectives, and information that are required to collect.

- Translation objectives into a serious of questions and inquires.

- Selection of the questionnaire's questions and trying them on a specific group of individuals, who are experienced in the construction sector to give their opinion about quality of questionnaire in terms of understanding, comprehension, and significance.

4) Brainstorming technique: It is a process to generate ideas and solutions through a collective debate about activities related to buildings works and engineering constructions of various kinds, the risks that building and construction projects are facing, and the effect of risks on (time, cost, and quality of the project). Brainstorming in the construction section can include management staff, controllers, execution engineers, suppliers, and essential parties of the project.

5) Delphi technique: It is one of the most important techniques, which are used to look into the project's future, to draw up policies, strategies, and alternatives for future perceptions of the risks that the construction sector could face. A carefully designing program is used in this technique, and it has several questionnaires, which will be given to experts in this sector while continuing to study them and getting a clearer picture of the project's future.

The third phase: risks analysis

Two methods of analysis will be used in this phase, and they are represented as follows:

First: qualitative analysis

It is the study and analysis of size and the extension of the effect of the potential risk on the project's objectives. In other words, risks are ordered according to how effective they are in the project's objectives (Schwalbe, 2007). The following tools are used in the process of qualitative risk analysis as indicated by (Schwalbe, 2012; Wallo, 2015; Zandhuis, 2013):

1) Probability and impact assessment: It deals with assessing risks probability in addition to the probable impact on the project's objectives, which are represented by time schedule, cost, quality along with negative impacts of modifications and positive impacts of opportunities. The probability and impact of each risk, which is recognized and identified is assessed.

2) Cause and effect diagram: It is a tool that provides a methodological way to look into the causes contributing to the occurrence of risks, which are represented by fishbone diagram. Cause and effect diagram is known as (Ishikawa diagram). It is a diagram that represents a module to display the associations between events (its effects) and many causes for them, where it explains the main problem that has to be solved in the head of the fishbone diagram and explains the causes in the bones, and branch to eventually reach secondary causes, where it graphically explains the relationship between the effect and all factors that could affect this result. 
3) Probability and impact matrix: It is a tool that is used by the project's team to help identify the probabilities of risks occurrence, and the impact resultant from the occurrence of these risks, and how impactful they are on the project's objectives, which help the project's team prepare a detailed plan to respond to risks of high significance or priority. Depending on this matrix, risks are divided into four types:

a) First type: Risks with low probability and low effect, which are often ignored.

b) Second type: Risks with high probability and low impact, which can be dealt with during carrying out the project.

c) Third type: Risks with low probability and high effect, which are highly significant risks. In case they happen, a contingency plan has to be made.

d) Fourth type: Risks with high probability and high effect, which have a high priority. These risks have to be paid careful attention by the project's team.

Second: quantitative analysis

It is providing a calculated quantitative description of the risk on the basis of probability of events and consequences resultant from the risk in a cash value or another value (AL-Sosi et al., 2017). The quantitative analysis has several methods, which are illustrated in the form (1-2)

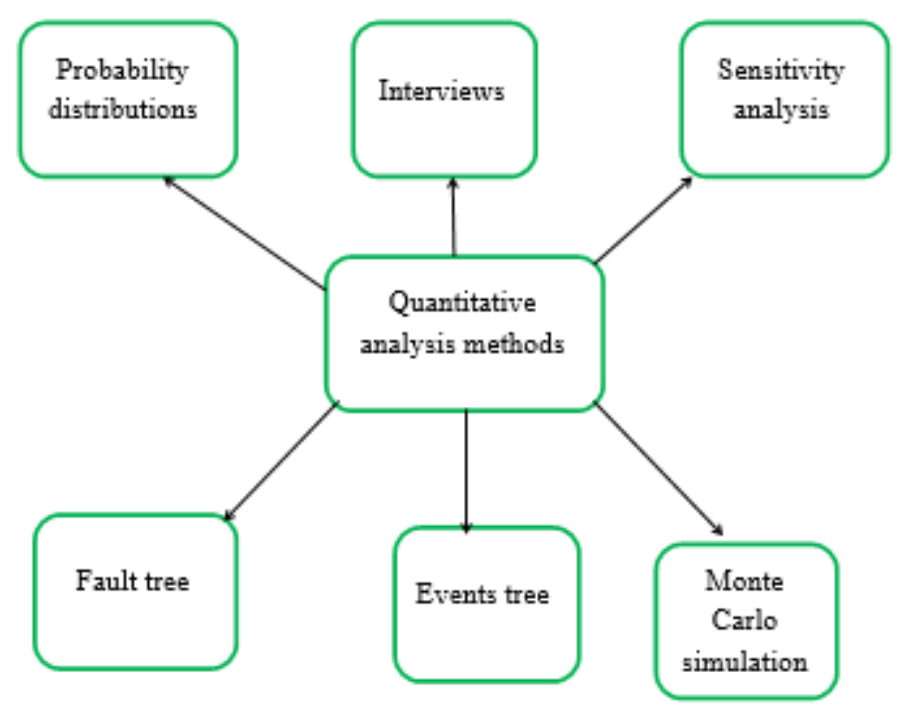

source: (AL-Sosi et al ,2017), risk assessment in construction projects inMisrata, first conference of industrial technique, Misrata university, Libya.

The fourth phase: planning the response to risks

It is the process of laying down options and procedures on the purpose of improving opportunities and reducing risks that threaten the project. It includes identifying and appointing one person or more who takes the responsibility for each response that has been agreed upon and then finance it (Ewelina, 2011). The strategies for response to risk are represented, as indicated by (Simu, 2006), as follows:

First: strategies for response to negative risks

1) Avoidance strategy: It is avoiding risks by changing the project management plan to completely eliminate threats through identifying time schedule, changing the strategy, or reducing the scope.

2) Transfer strategy: It means transferring some or all negative risks to a third party

3) Reduction strategy: This means reducing the risk effect so that it would be within the accepted limits.

4) Acceptance strategy: This means drawing up a contingency plan and dealing with the reserves of the contingency plan to tackle the risks.

Second: strategies for positive risks 
1) Exploit strategy: seizing the opportunity, and taking advantage of it, such as time reduction, or cost reduction.

2) Sharing strategy: engaging a third party to grasp the opportunity and achieve the project's objectives.

3) Improvement strategy: increasing the probability of seizing opportunity such as increasing resources of one of the activities so that it is performed early.

4) Acceptance strategy: getting ready to make advantage of an opportunity in case it occurs.

5) Emergent response strategy: some responses are prepared, i.e. they are not used except if events, which are previously defined happened.

The fifth phase: risks control and check

It is the process in which risks that appear lately are identified, analyzed, or planned while following up known risks, and risks listed in control list, and reanalyzing the ongoing risks, following up conditions that operate contingency plans, following up remaining risks, reviewing the execution of risk responses, and assessing its effectiveness at the same time.

\section{Conclusions and Study Recommendations}

\subsection{Study Conclusions}

The summary concluded from the study lies in the theoretical study of construction projects' risks. Building and construction projects are considered to be of a special nature. One of its most important aspects is the length of time, which leads to a change in circumstances since there are many phases of the construction project's life cycle, starting from project beginning phase, to planning phase, execution phase, following up phase, and ending with closing phase. Therefore, it contains many risks, which are related to different factors, such as legal, organizational, technical, zoning, financial, social and political ones. A negative effect on the desired, expected, and hoped result stems from these risks. Risk management in construction project takes the responsibility for planning, organizing, guiding, and controlling risks to reduce and control the negative effects resultant from them. The process of management of project risk analysis includes many phases. The first phase is planning through which a way to apply construction projects risk management is identified. The second phase is risk identification, which aims to discover and recognize all the potential risks that the construction project is exposed to through the following tools: personal interview, checklist analysis, questionnaire, brainstorming technique, and Delphitechnique. The third is a phase in which two methods of risk analysis are used. The first method is the qualitative risk analysis, which aims at studying the range of effect through using the following tools: probability and impact assessment, cause and effect diagram, probability and impact matrix, whereas the second is the quantitative analysis, which aims to provide a calculated quantitative description of the risk by using the following tools: interviews, sensitivity analysis, Monte Carlo simulation, events diagram, fault diagram, and probability distributions. The fourth phase is planning a response to risks, and it aims at drawing up strategies for risk. These strategies are divided into two groups: The first is strategies for response to negative risks [avoidance strategy, transfer strategy, reduction strategy, and acceptance strategy]. The second group is strategies for response to positive risks [exploit strategy, sharing strategy, improvement strategy, acceptance strategy, and emergent response strategy]. The fifth phase is risks control and check, and it aims to follow up and analyze recent risks.

\subsection{Recommendations of the Study}

Depending on the conclusions, the study recommends the following:

i.First main recommendation:

- Processes of assessing the efficiency of construction companies should be carried out by a qualified group, which is capable of studying bases and required conditions in the construction companies. The study recommends the use of the following basic and secondary standards in the assessment process:

1. Financial standard $\rightarrow$ secondary standards:

a) Current bank accounts.

b) Continuity of current accounts without interruption.

c) Cash liquidity.

d) A Detailed account of movable and immovable assets.

2. Company's experience and reputation standard $\rightarrow$ secondary standards: 
a) Previous failed projects.

b) Suits brought against the company.

c) Previous or current projects similar to the current project's data.

d) A making good certificateof theprevious projects.

e) Number of projects similar to the current project to be carried bout.

3. Material resources standard $\rightarrow$ secondary standards:

a) Possession of necessary equipment and supplies for the work.

b) Readiness of technical status of machines.

c) A specialized maintenance department for machines and equipment.

4. Managerial standard $\rightarrow$ secondary standards:

a) A complete organizational hierarchy of the company.

b) Complete engineering specializations of the project to be carried out.

c) Continuity of the company's work as a main contractor.

d) Continuity of the company's work as a secondary contractor.

5. Technical standard $\rightarrow$ secondary standards:

a) Availability of trained, professional staff who is experienced in construction projects.

b) Use of proper assessment for secondary contractors (subcontractor).

c) Conducting an interview with subcontractors to ensure that they understand and comprehend the project circumstances and the surrounding environment.

6. Planning and follow-up standard $\rightarrow$ secondary standards:

a) Department of research and development.

b) A system for controlling and assessing the executed works in the project.

c) The ability to plan and schedule technical processes of the project using modern technology.

7. Safety and insurance standard $\rightarrow$ secondary standards:

a) Previous incidents of the decease of a worker.

b) Certificates ofinsurance on the construction projects

c) Availability of programs for security and safety in the site.

d) Availability of training programs to prevent accidents.

e) Availability of fire protection system and alarm systems.

f) Availability of the necessary procedures and means to deal with hazardous materials.

g) Availability of programs of first procedures to help in case of emergencies.

Second main recommendation:

- Use qualitative analysis method through [personal interview tool, checklist analysis tool, questionnaire tool, brainstorming technique and Delphi technique] in the process of diagnosis, analysis and categorization of risks in the process of risk management.

Third main recommendation

- Use the quantitative analysis method through [interviews, sensitivity analysis, Monte Carlo simulation, events tree and fault tree events] in the process of quantitative description analysis [cash, other value] resultant from risks.

Fourth main recommendation

- Holding training courses on risk management, introducing risk management into the higher education curriculum and enrolling construction project team for training courses related to risk management according to their major.

Fifth main recommendation: 
- Studying types of contracts and contract expressions thoroughly to identify risks that each party bears in the construction project according to the specific contract to transfer risks to the party that is more capable of managing it in a better way.

\section{Refernces}

Akab, S. (2009). Study the design and Implementation Factors that Lead to increase the cost risk, During the implementation Phase of Constraction Projects. Journal Engineering and Technolgy, 27(2).

Al- Sosi, A., Al- Ne`ave, O. Baeli, I., \& Shtwan, Ali. (2017). Risk Assessment in Construction Projects, Faculty of Engineering, Misurata University.

Ali, S., \& Nima, N. (2017). Project Risk analysis According to professional Project management System. Faculty of Business Economics, The two rivers: Iraq.

Al-Rejeedh, J. (2016). Insurance and Risk Management, Management, Mars Publishing house: Riyadh.

Al-Sheikh, K., \& Zedan, Z. (2015). Projects Management, Higher Institute for administrative Development. University of Damascus.

Dave, H., \& David, H. (2002). Universal Risk Project. Risk Management Institute: UK.

Ewelina, W. (2011). Risk Management- Practices in A Construction Project: A Case Study. Master Thesis, Chalmers Univesity of Technology, sweden.

Gabel, M. (2013). Project Risk Management Guidance For WSDOT Projects. Washington State Department of Transportation Administrative and Engineering Publication.

Hamad, T. (2003). Risk management. University House: Egypt.

Hamadeh, M., Nayeth, M., \& Amori, O. Risk Management. Damascus Journal of Engineering Sciences, 28(1).

Loader, D. (2006). Advance Operations Management. John Wily and ltd: England.

Marco, A., \& Thaheem, M. (2014). Risk Analysis in Construction Projects: A practical Selection Methodology. American Journal of Applied Sciences, 11(1). https://doi.org/10.3844/ajassp.2014.74.84

Meredith, J., Mantel, R., \& Samuel, J. (2012). Project Management: A Managerial Approach. John wily and Sons Singapore Pte. Ltd. Printed in Asia.

Migdadi, A. (2016). Knowledge Areas and ITTo, How to Become A Certified Project Management Professional. "Section Four, Exam Tips, Tools and Study Materials, Printed USA.

Musa, Sh., Nori, M., Ibrahim, N., Mohammad, H., \& Samir, S. (2012). Risk Management. Copy right wael for Publishing: Jordan.

Nepal, B. (2014). Time Management in Project: Tool, Techniques and Methods. Norwegion University of Science Technology, Department of Production and Quality Engineering.

Pieplow, B. (2012). Project risk Management Hand Book: A Scalable pproach. Version 1, Scalable Project Risk Management.

Qasem, S. (2012). The Project Integration Management, CSC- IT Project Management, printed in United State.

Raftery, J. (2003). Risk analysis in project Management. Second Edition, Andrewwon Marketing Department; London. https://doi.org/10.4324/9780203474556

Schwalbe, K. (2007). Information Technology Project Management. Sixth Edition: USA.

Schwalbe, K. (2012). Information Technology Project management. Seventh Edition: USA.

Simu, K. (2006). Risk management in Small Construction project, Lulea university of Technology Department of Civil and environmental engineering, Divesion of Architecture and Infrastructure.

Sonmez, M. (2002). Applying Evidential Reasoning to Prequalifying Construction Contractors. Journal of Management in Engineering, 18(3). https://doi.org/10.1061/(ASCE)0742-597X(2002)18:3(111)

Tetteh, I. (2014). Risk Management in Construction Project. Master thesis. Masaryk University: Czech.

Varsha, W., Siddhi, H., \& Kahave, R. (2015). A Review: Fishbone Diagram. World Journal of Pharmacutcal Research.

Wallo, M. (2015). Structuring Construction Project Management process: A Case Study of a Swedish House Developer, master of Science Thesis, Sweden. 
Williams, M. (2008). The principles of project management First Edition, Published Wideman; Canada.

\section{Copyrights}

Copyright for this article is retained by the author(s), with first publication rights granted to the journal.

This is an open-access article distributed under the terms and conditions of the Creative Commons Attribution license (http://creativecommons.org/licenses/by/4.0/). 